\title{
Brain dopamine response in human opioid addiction
}

Mark R. C. Daglish, Tim M. Williams, Sue J. Wilson, Lindsay G. Taylor, Chin B. Eap,

Marc Augsburger, Christian Giroud, David J. Brooks, Judy S. Myles, Paul Grasby,

Anne R. Lingford-Hughes and David J. Nutt

\section{Background}

Drugs of dependence cause dopamine release in the rat striatum. Human neuroimaging studies have shown an increase in dopamine in the equivalent region in response to stimulants and other drugs.

\section{Aims}

We tested whether opioids provoke dopamine release and its relationship to the subjective experience.

\section{Method}

In two combined studies 14 heroin addicts on methadone maintenance treatment underwent two positron emission tomography brain scans of the dopamine system using $\left[{ }^{11} \mathrm{Cl}\right]$-raclopride following an injection of placebo and either $50 \mathrm{mg}$ intravenous diamorphine or $10 \mathrm{mg}$ subcutaneous hydromorphone in a double-blind, random order design.

\section{Results}

Both opioids produced marked subjective and physiological effects, but no measurable change in $\left[{ }^{11} \mathrm{C}\right]$-raclopride binding.

\section{Conclusions}

The absence of a dopamine response to opioid agonists contrasts with that found with stimulant drugs and suggests dopamine may not play the same role in addiction to opioids. This questions the role of dopamine in the subjective experience of heroin in opioid addicts.

\section{Declaration of interest}

None. Funding detailed in Acknowledgements.
Preclinical studies suggest that the rewarding properties of misused drugs relate to their ability to provoke dopamine release in the meso-cortico-limbic system. Previous $\left[{ }^{11} \mathrm{C}\right]$-raclopride positron emission tomography (PET) studies in humans have demonstrated this effect for stimulants, ${ }^{1}$ nicotine ${ }^{2}$ and alcohol. ${ }^{3}$ The 'high' following intravenous methylphenidate is correlated with dopamine release. ${ }^{4}$ However, dopamine release has not always been found to be associated with opioids nor critical in opioid drug-seeking behaviour in rodents. ${ }^{5,6}$ Dopamine response has also been shown to be blunted in dependent stimulant users. ${ }^{7}$ The aim of our PET studies was to simultaneously measure the subjective responses and objective effects of two opioid agonists (heroin and hydromorphone), and dopamine release in heroin addicts maintained on methadone. We predicted that injected opioids would induce a subjective 'high', which would correlate with the reduction in $\left[{ }^{11} \mathrm{C}\right]$-raclopride binding.

\section{Method}

\section{Patients}

We recruited out-patients from local drug treatment services. All participants fulfilled ICD-10 criteria for opioid dependence, ${ }^{8}$ were male, over 18 years old, current cigarette smokers and were maintained on methadone prescription at a minimum dose of $15 \mathrm{mg} /$ day. Potential participants were excluded if they fulfilled diagnostic criteria for any other mental disorder except nicotine dependence, had a history of current regular stimulant use or were prescribed any medication other than methadone. A past history of neurological disorder, significant head injury or other current medical illness were also exclusion criteria.

All participants gave written informed consent and studies were approved by local hospital research ethics committees and the UK Administration of Radioactive Substances Advisory Committee.
In study 1 , the hydromorphone challenge, we recruited nine individuals on methadone maintenance treatment. Two were subsequently excluded from the analysis for testing positive to stimulants at the time of scanning and one withdrew. In study 2 , the heroin challenge, ten participants on methadone maintenance treatment were recruited. One person was excluded for testing positive to cocaine at the time of scanning and one withdrew. Therefore, six people completed study 1 and eight people completed study 2. Further demographic details are presented in Table 1. Participants were recruited from the same out-patient population but three of the demographic measures showed statistically significant differences between the two groups. None of these differences survived correction for the 28 comparisons and probably represent chance differences.

\section{Scanning protocol}

Each person underwent two $\left[{ }^{11} \mathrm{C}\right]$-raclopride PET scans of dopamine $\mathrm{D}_{2}$-receptor availability 1 to 4 weeks apart (mean 13 days) determined by scanner availability. To induce similar levels of expectancy in each condition, participants were told that they would receive either an injection of opioid drug or saline prior to being scanned on each occasion. In fact, each person received one opioid pre-treatment (opioid scan) and one placebo pretreatment (placebo scan) in random order. The first participant in study 1 had half his usual methadone dose on the morning of the scan, whereas the other participants had no methadone on the day of the scan and were therefore approximately $24-26 \mathrm{~h}$ after last dose when scanned. In study $1,10 \mathrm{mg}$ hydromorphone was given by subcutaneous injection over $20 \mathrm{~s}, 15 \mathrm{~min}$ before tracer injection; in study 2, $50 \mathrm{mg}$ diamorphine was given by intravenous injection over $20-30 \mathrm{~s}, 5 \mathrm{~min}$ before tracer injection.

All scans were performed on a brain dedicated CTI/Siemens EXACT3D scanner (Knoxville, Tennessee). Positron emission tomography images were acquired for $90 \mathrm{~min}$ after a $30 \mathrm{~s}$ bolus 


\begin{tabular}{|c|c|c|c|}
\hline Measure & $\begin{array}{c}\text { Study } 1 \\
\text { (hydromorphone) }\end{array}$ & $\begin{array}{l}\text { Study } 2 \\
\text { (heroin) }\end{array}$ & Total \\
\hline Age, years: mean (s.d.) & $32.6 \quad(4.96)$ & $34.7 \quad(9.69)$ & \multirow{2}{*}{33.8 (7.82) } \\
\hline Daily methadone dose, mg/day: mean (s.d.) & $\begin{array}{l}32.6(4.96) \\
46.7(13.2)\end{array}$ & $40.6(10.2)$ & \\
\hline Duration of opioid use, years: mean (s.d.) & $10.7(4.30)$ & $12.4(8.60)$ & $11.6(6.80)$ \\
\hline \multicolumn{4}{|l|}{ EPQ-R: mean (s.d.) } \\
\hline Neuroticism & $17.3(2.25)$ & $11.4(6.95)$ & $14.6(5.97)$ \\
\hline Extroversion & $12.3(5.72)$ & $13.0(5.16)$ & $12.7 \quad(5.20)$ \\
\hline Psychoticism & $9.50(5.21)$ & $10.3(2.69)$ & $9.92(3.88)$ \\
\hline Lie Scale & $5.50(3.15)$ & $6.71(3.90)$ & $6.15(3.48)$ \\
\hline Addiction & $19.2(4.45)$ & $14.3(5.22)$ & $16.5(5.32)$ \\
\hline Criminality & $19.3(3.88)$ & $13.7 \quad(5.65)$ & $16.3(5.54)$ \\
\hline \multicolumn{4}{|l|}{ EPQ-IVE: mean (s.d.) } \\
\hline Empathy & $11.3(3.78)$ & 10.3 & $10.8(4.19)$ \\
\hline Venturesomeness & $9.83(4.36)$ & $12.7(1.70)$ & $11.4(3.40)$ \\
\hline Impulsiveness & $9.00(4.29)$ & $10.0(3.96)$ & $9.54(3.97)$ \\
\hline \multicolumn{4}{|l|}{ Opioid OCDS: mean (s.d.) } \\
\hline Obsessional thoughts & $12.6(4.31)$ & $9.29(7.11)$ & $10.9(5.90)$ \\
\hline Compulsive use & $18.29(7.57)$ & $12.71(8.2)$ & $15.5(8.11)$ \\
\hline \multicolumn{4}{|l|}{ MOS-SF36: mean (s.d.) } \\
\hline Physical functioning & $74.2(24.0)$ & $70.6(39.5)$ & $72.1(32.6)$ \\
\hline Role functioning - physical & $40.0(37.9)$ & $84.4(18.6)$ & $67.3(34.4)^{\star}$ \\
\hline Bodily pain & $58.8(21.4)$ & $60.5(30.1)$ & $59.9(26.1)$ \\
\hline General health & $53.4(24.2)$ & $60.8(23.6)$ & $57.9(23.1)$ \\
\hline Vitality & $42.0(11.5)$ & $60.8(23.6)$ & $57.9(23.1)$ \\
\hline Social functioning & $23.3(14.9)$ & $36.8(9.36)$ & $31.6(13.1)$ \\
\hline Role functioning - emotional & 66.7 (33.3) & $75.0(29.6)$ & $71.8(30.0)$ \\
\hline Mental health & $36.7 \quad(8.16)$ & $51.7 \quad(7.35)$ & $45.9(10.6)^{* *}$ \\
\hline \multicolumn{4}{|l|}{ Spielberger: mean (s.d.) } \\
\hline Placebo scan State Anxiety & $42.3(11.1)$ & $32.3(11.3)$ & $36.6(11.9)$ \\
\hline Placebo scan Trait Anxiety & $47.7(10.1)$ & $35.3(10.1)$ & $41.0(11.9)$ \\
\hline Drug scan State Anxiety & $42.2(10.4)$ & $34.3(9.88)$ & $37.6(10.5)$ \\
\hline Drug scan Trait Anxiety & $48.2(11.7)$ & $36.8 \quad(7.89)$ & $41.6(11.0)^{*}$ \\
\hline \multicolumn{4}{|l|}{ BDI: mean (s.d.) } \\
\hline Placebo scan & $15.2(10.3)$ & 12.4 & $13.6(7.79)$ \\
\hline Drug scan & $17.0(11.6)$ & $11.0(8.85)$ & $13.8(10.3)$ \\
\hline
\end{tabular}

injection of $120 \mathrm{MBq} \quad\left[{ }^{11} \mathrm{C}\right]$-raclopride, using list-mode acquisition. Dynamic images were rebinned into 26 frames of variable length from $5 \mathrm{~s}$ increasing to $5 \mathrm{~min}$ towards the end of the scan. Images were reconstructed using filtered back projection with a ramp filter. A matching pair of images was created for each scan, one with measured attenuation correction from a pre-scan transmission image, and the second with no attenuation correction for frame-by-frame realignment.

\section{Image analysis}

Statistical Parametric Mapping 2 (SPM2; Wellcome Department of Imaging Neuroscience, Institute of Neurology, University College London, UK) was used to realign the non-attenuation corrected image frames to the fourth time-frame in the image sequence. This was done to correct for the individual's head movement during the scan. The first three frames were not included owing to insufficient signal in the images. It was assumed that the majority of head movement would occur during the later part of the $90 \mathrm{~min}$ scanning procedure, and that there would be minimal movement during the first $1 \frac{1 / 2}{2}$ min prior to frame 4 . These realigned images were used to create a mean image, to which all frames were then again realigned. The realignment parameters generated from this procedure were then applied to the attenuation corrected images. This procedure was used because the non-attenuation corrected images have substantially more structural information, which enables better realignment between frames and is less susceptible to changes in tracer distribution being misinterpreted as head movement by the realignment algorithm.

The realigned attenuation corrected images were then processed with Receptor Parametric Mapping software developed in-house to generate images of $\left[{ }^{11} \mathrm{C}\right]$-raclopride binding potential using the cerebellum as a reference region. ${ }^{9}$ Binding potential of $\left[{ }^{11} \mathrm{C}\right]$-raclopride is related to the density of available dopamine $\mathrm{D}_{2}$-receptors. We also generated an add-image derived from a weighted sum of all frames. Regions of interest corresponding to the putamen, caudate and ventral striatum in each hemisphere were drawn onto a template add-image in standard space according to published criteria. ${ }^{10}$ The add-image for each person was then warped to match a template image in a standardised space using the normalisation algorithms from SPM2. The warping parameters for this transformation were then inverted using the SPM2 deformations toolbox and applied to the standardised regions of interest. This process creates an automated individualised region of interest definition for each participant's brain images. These regions of interest were then used to sample the mean binding potential in each region in each scan. All image analysis was implemented in Matlab (The Mathworks Inc., Natick, Massachusetts) running on a Linux PC. 


\section{Physiological and subjective measures}

At the start of the study participants completed questionnaires on general health (Medical Outcomes Study Short Form 36, UK version), ${ }^{11}$ personality (Eysenck Personality Questionnaire, Eysenck Impulsiveness-Venturesomeness-Empathy Scale, ${ }^{12}$ Severity of Dependence Scale, ${ }^{13}$ an adapted version of the Obsessive-Compulsive Drinking Scale tailored to measure obsessive thoughts of using opioids, compulsive opioid using behaviour, and allowing for mode of drug delivery ${ }^{14}$ ), and lastly a drug use profile.

Before each scan participants completed questionnaires on current subjective state (mood visual analogue scales), the Addiction Research Centre Inventory 49-item short form (ARCI), ${ }^{15}$ Adjective Checklist, ${ }^{16}$ State-Trait Anxiety Inventory, ${ }^{17}$ Beck Depression Inventory, ${ }^{18}$ plus an observer-rated opiate withdrawal scale previously described. ${ }^{19}$

During each scan, data were collected using visual analogue scales on 'sleepy', 'urge' (to use heroin), 'craving' (for heroin), 'gouched' (local slang for opioid intoxication), (heroin) 'withdrawal', 'high' and 'rush'. These symptoms were rated on a 100-point scale at baseline, $5 \mathrm{~min}$ prior to injection and at 5, 15, 30, 45, 60, 75 and $90 \mathrm{~min}$ post-injection. Highly correlated (Pearson's $r>0.85$ ) measures were combined to produce composite scores of 'sleepy', 'crave/urge', 'gouched/high', 'withdrawal' and 'rush' feelings. For each of these feelings scores we calculated an area under the curve measure of change from baseline, using a trapezoidal function, for the 90 min scan and then compared heroin and placebo scans using paired $t$-tests. These data were also subjected to a repeated measures ANOVA with time and scan condition as within-participants factors and active drug as the between-participants factor.

After each scan, participants completed questionnaires on change in current subjective state following the injection (ARCI, Adjective Checklist, mood scale) and which dose of opioid they felt they had had before the scan. All questionnaire data were analysed using either paired $t$-tests or repeated measures ANOVA.

We used the previously published method $^{20}$ to measure saccadic eye movements at baseline, $5 \mathrm{~min}$ before injection of heroin or placebo and at 5, 15, 30, 45, 60, 75 and 90 min after injection. Participants were also monitored throughout with pulse oximetry for safety.

Plasma samples for estimation of pre-scan methadone levels and post-injection hydromorphone or heroin levels were taken at baseline, then $1 \mathrm{~min}$ before and $20 \mathrm{~min}$ after scan start. The plasma concentrations of (R)- and (S)-methadone, of hydromorphone, 6-monoacetyl morphine (6-MAM), morphine 6-glucuronide (M6G) and morphine were measured by liquid chromatography coupled with mass spectroscopy as previously described. ${ }^{21,22}$

All statistical tests were implemented in SPSS for Windows, version 14.0

\section{Results}

\section{Subjective measures}

Figure 1 shows the area under the curve (AUC) of change from baseline measures of the visual analogue scales in response to placebo (both groups combined), hydromorphone and heroin injections.

Analysis with a repeated measures general linear model showed that the 'sleepy' scores showed no interaction with, or main effect of, drug given (i.e. diamorphine or hydromorphone), although there was a main effect of condition (i.e. drug $v$. placebo; $F=6.637, P=0.026)$. There was also a significant interaction of condition (drug $v$. placebo $) \times$ time $(F=5.149, P<0.002)$ and a main effect of time from $15 \mathrm{~min}$ after scan start until the end of the scanning session $(F>7.60, P<0.02)$. Essentially, all participants became sleepier while lying still in a darkened room over time; this effect was more exaggerated following an injection of heroin or hydromorphone compared with placebo, but there was no difference between the two drugs.

The withdrawal scores showed a characteristic pattern of starting at a low level at baseline which continued unchanged during the placebo scans, but reduced to near zero following hydromorphone and completely to zero following heroin. However, this did not separate from the placebo response on

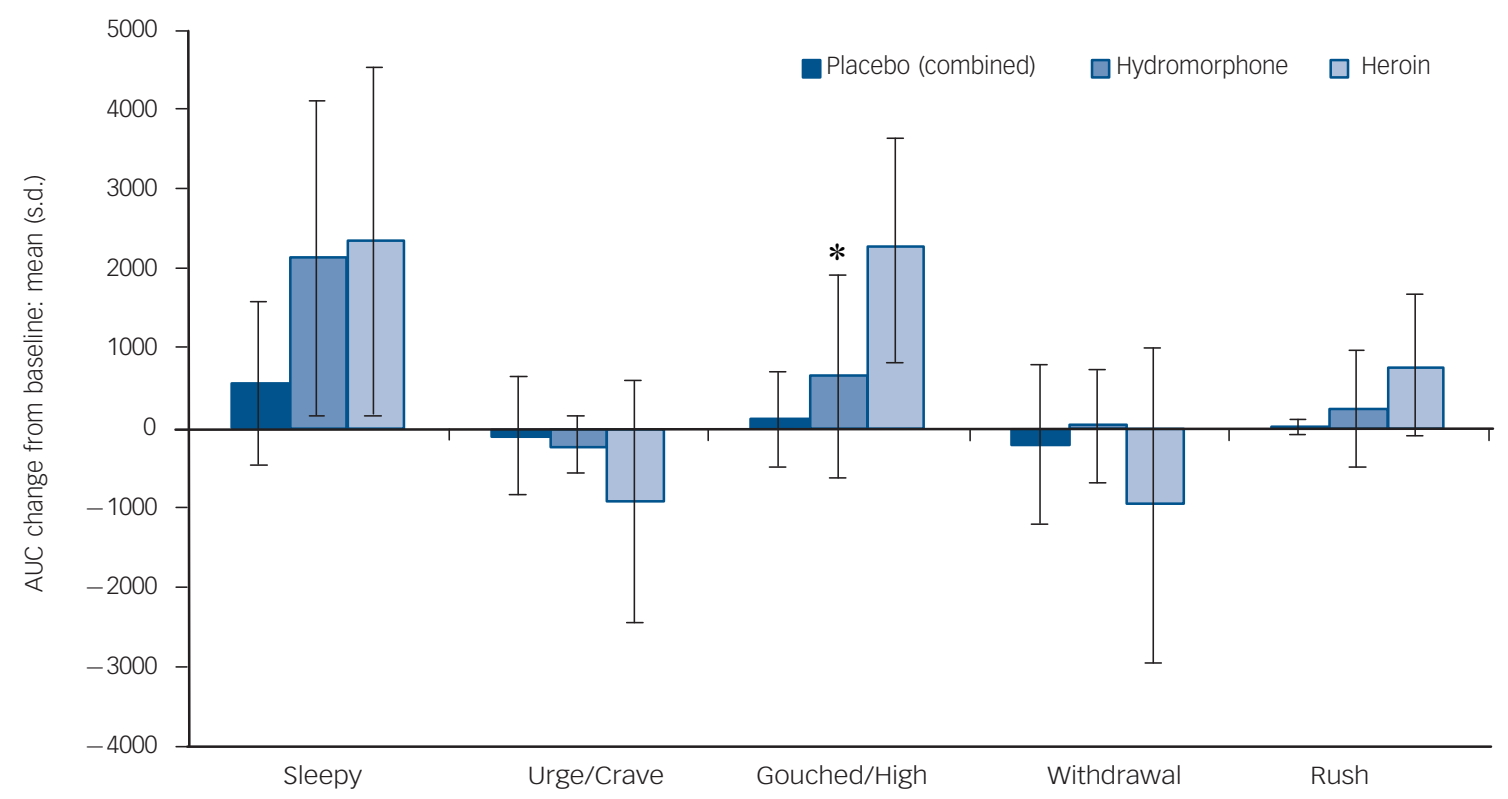

Fig. 1 Subjective effects of injection of hydromorphone (10 mg subcutaneously), heroin ( $50 \mathrm{mg}$ intravenously) or placebo. Measures are area under the curve (AUC) of change from baseline over $90 \mathrm{~min}$ following injection. ${ }^{*} P<0.05$ paired $t$-test, two-tailed: heroin $v$. placebo $(n=8)$ 
statistical testing. The same pattern was observed for the combined 'craving/urge' scores.

Participants showed dramatic and significant increases in the combined subjective measure of 'high/gouched' following injection of both opioids, which was significant for a condition $\times$ time interaction at all time points following the injection $(F>6.93$, $P<0.03)$. This also showed a significant main effect of condition $(F=15.3, P=0.002)$.

The subjective experience of 'rush' also showed an expected pattern of response with a significant condition $\times$ time interaction only at the first time point post-injection $(F=5.81, P=0.035)$. There was again a significant main effect of condition $(F=6.54$, $P=0.027)$. Visually, the 'rush' response to heroin was more dramatic than the response to hydromorphone immediately following the injections, but this did not show statistical separation. A significant increase $(F=14.6, P=0.004)$ was also seen in the Adjective Checklist 'agonist' scale but in no other subjective measures (Table 2).

All participants underestimated the opioid dose they had received. The group who received hydromorphone $35 \mathrm{mg}$ subcutaneously reported it as either water or $0.2 \mathrm{~g}$ 'street' heroin in equal numbers. The heroin group all reported their dose of $50 \mathrm{mg}$ intravenous diamorphine as equivalent to $0.2 \mathrm{~g}$ 'street' heroin (about $20 \mathrm{mg}$ diamorphine at current estimated street purity). Only one person misidentified the placebo injection as active and equivalent to $0.2 \mathrm{~g}$ 'street' heroin.

\section{Physiological measures}

\section{Saccadic eye movement changes}

Injections of both hydromorphone and heroin produced the expected decreases in saccadic eye movement peak velocity, as shown in Fig. 2. There was also a larger than usual placebo response, probably related to the scanner environment and enforced supine position, compared with that seen in our previous clinical studies. ${ }^{20}$ Many of the participants, particularly following heroin injection, became too intoxicated to be able to comply with the task of following the light with their gaze. This resulted in many missing data points and we were therefore unable to statistically test the effect of the drugs. Similar effects were found for measures of peak acceleration, peak deceleration and acceleration:deceleration ratio (data not shown). For the same

\begin{tabular}{|c|c|c|c|c|c|}
\hline \multirow[b]{2}{*}{ Adjective Checklist } & \multicolumn{2}{|c|}{ Hydromorphone } & \multicolumn{2}{|c|}{ Heroin } & \multirow{2}{*}{$\begin{array}{l}\text { Condition } \times \text { time } \\
\text { interaction }\end{array}$} \\
\hline & Pre-scan & Post-scan & Pre-scan & Post-scan & \\
\hline Agonist & & & & & $F=14.6$ \\
\hline Placebo scan: mean (s.d.) & 18.8 (4.49) & $16.6(2.3)$ & $22.43(5.86)$ & $20.43(5.97)$ & d.f.=1, \\
\hline Drug scan: mean (s.d.) & $18.83(4.88)$ & $29.4 \quad(7.44)$ & $23.29(7.93)$ & $26.14(7.78)$ & $P=0.004$ \\
\hline Withdrawal & & & & & NS \\
\hline Placebo scan: mean (s.d.) & $16.2(9.26)$ & $9.6 \quad(6.31)$ & $4.43(4.12)$ & $7.14(6.09)$ & \\
\hline Drug scan: mean (s.d.) & $14.17(9.47)$ & $15.6(21.36)$ & $3.14(3.08)$ & 3.57 (3.74) & \\
\hline
\end{tabular}

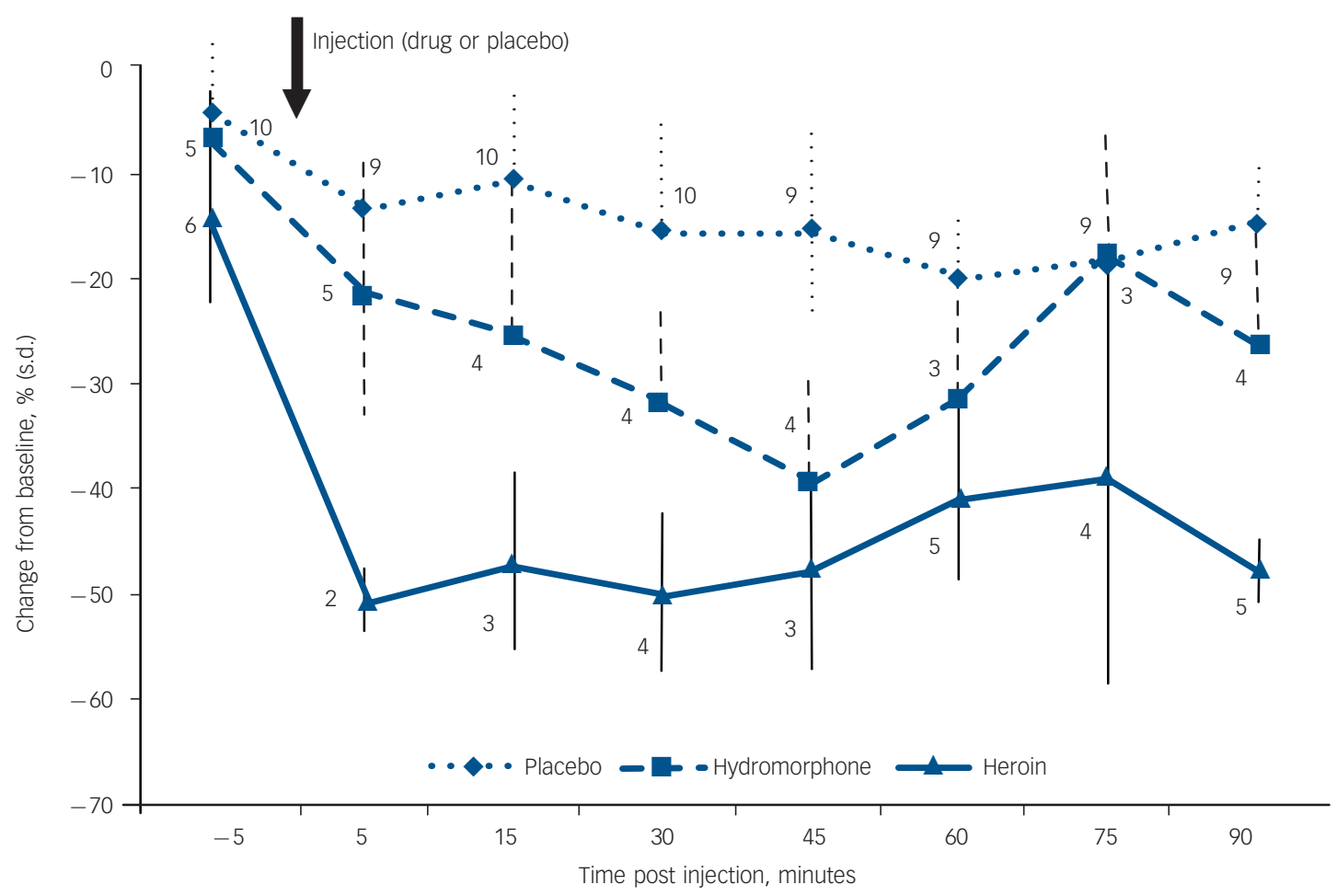

Fig. 2. Percentage reduction in peak velocity saccadic eye movement following injection of placebo, $10 \mathrm{mg}$ subcutaneous hydromorphone or $50 \mathrm{mg}$ intravenous heroin. Numbers are number of participants able to complete the task: maximum 10 for placebo 5 for hydromorphone and 6 for heroin. 


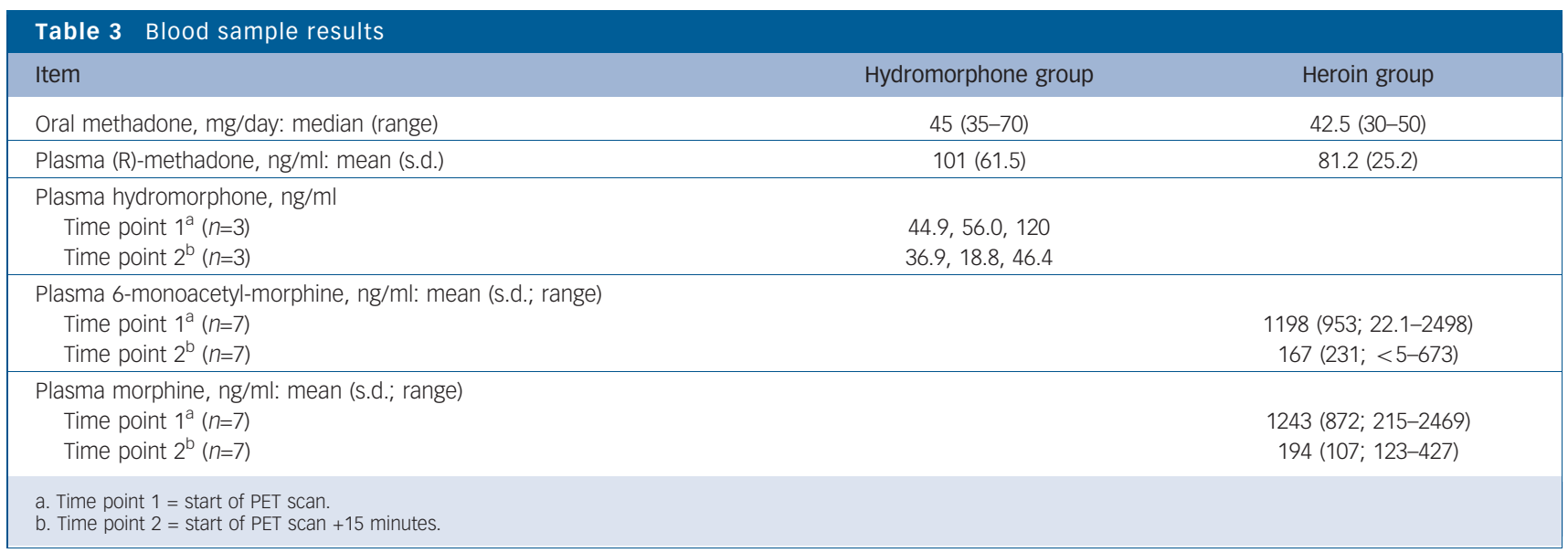

reasons, it was not possible to examine the relationship between blood levels of injected opioid or oral methadone and the saccadic eye movement data.

\section{Blood levels}

Opioid levels in the blood samples are described in Table 3. Owing to a freezer failure, only two of the six participants from study 1 and six of the eight participants from study 2 had a complete set of blood sample data. There was no significant difference in plasma methadone levels pre-scan on the two scan days on paired $t$-test, and therefore the levels were averaged where both samples were available, or the single available sample was used where one sample had been lost. For all 12 participants with sufficient data, there was a clear correlation between daily oral methadone dose and plasma level pre-scan (Pearson's $r=0.65, P=0.02$ ).

\section{Raclopride scans}

Mean values for $\left[{ }^{11} \mathrm{C}\right]$-raclopride binding potential for the six regions are presented in Table 4. For comparison, data from five historical control scans, retrieved from the library at the Medical Research Council Cyclotron Unit and analysed to the same protocol, are included. This group were healthy controls, scanned on the same PET camera with a similar scanning protocol although no drug or placebo was administered. No significant changes in $\left[{ }^{11} \mathrm{C}\right]$-raclopride binding potential were found in response to heroin or hydromorphone injection.

\section{Discussion}

This is the first study to examine whether opioids increase dopamine levels in human opioid addicts as has been reported with other misused drugs. We detected no increase in striatal dopamine levels despite marked objective opioid effects of slowed eye movements and a pronounced subjective level of intoxication including a 'high/gouched' and 'rush'. This dissociation implies that dopamine may not be critical in mediating the 'high' from opioids in dependent humans. Stimulant drugs and opioids are generally considered to be approximately equal in their ability to cause dependence ${ }^{23}$ and several studies have shown that cocaine and amphetamine measurably reduce $\left[{ }^{11} \mathrm{C}\right]$-raclopride binding in humans - an indirect measure of dopamine release, ${ }^{1,4,7}$ as well as profoundly increasing dopamine in rodents. ${ }^{6}$ The high dose of heroin given in our second study produced marked subjective effects that were of similar magnitude to those reported for cocaine when given in the scanner environment. ${ }^{1}$ Despite this, there was no corresponding effect on $\left[{ }^{11} \mathrm{C}\right]$-raclopride binding. In addition, we showed a dose-response relationship of the subjective and physiological measures to the two different opioids.

Table $4 \quad\left[{ }^{11} \mathrm{C}\right]$-Raclopride binding potentials for the hydromorphone group, the heroin group, a group of historical controls $(n=5)$ and the single participant from study 1

\begin{tabular}{|c|c|c|c|c|c|c|}
\hline & \multicolumn{2}{|c|}{ Caudate } & \multicolumn{2}{|c|}{ Putamen } & \multicolumn{2}{|c|}{ Ventral striatum } \\
\hline & Right & Left & Right & Left & Right & Left \\
\hline \multicolumn{7}{|c|}{ Hydromorphone: mean (s.d.) } \\
\hline Placebo & $2.65(0.45)$ & $2.79(0.35)$ & $2.74(0.35)$ & $2.73(0.33)$ & $2.26(0.22)$ & $2.45(0.31)$ \\
\hline Drug & $2.58(0.33)$ & $2.73(0.24)$ & $2.64(0.37)$ & $2.70(0.31)$ & $2.23(0.29)$ & $2.41(0.15)$ \\
\hline \multicolumn{7}{|c|}{ Heroin: mean (s.d.) } \\
\hline Placebo & $2.61(0.34)$ & $2.67(0.23)$ & $2.78(0.23)$ & $2.80(0.23)$ & $2.21(0.33)$ & $2.48(0.31)$ \\
\hline Drug & $2.71(0.45)$ & $2.78(0.41)$ & $2.83(0.31)$ & $2.87(0.26)$ & $2.06(0.47)$ & $2.47(0.38)$ \\
\hline \multicolumn{7}{|c|}{ Historical controls: mean (s.d.) } \\
\hline Placebo & $2.49(0.29)$ & $2.52(0.21)$ & $2.79(0.32)$ & $2.79(0.34)$ & $2.28(0.12)$ & $2.33(0.23)$ \\
\hline \multicolumn{7}{|c|}{ Single participant: ${ }^{a}$ mean (s.d.) } \\
\hline Placebo & 1.61 & 1.76 & 1.67 & 1.66 & 1.4 & 1.58 \\
\hline Drug & 1.89 & 2.02 & 1.82 & 1.94 & 1.66 & 1.73 \\
\hline
\end{tabular}




\section{Dopamine responses to 'addictive' stimuli}

That cocaine, amphetamine and methylphenidate induce measurable decreases in human $\left[{ }^{11} \mathrm{C}\right]$-raclopride binding is not surprising, as these drugs act directly at the dopamine synapse to increase dopamine levels. However, increases in dopamine release, inferred from reduced tracer binding, have also been reported with alcohol in non-dependent drinkers ${ }^{3}$ and smoking in dependent smokers, ${ }^{2}$ neither of which directly releases dopamine. The implication from our study is that any dopamine release in response to heroin cannot be of the same magnitude as these other provoking stimuli.

A notable difference between our studies and many of the previous experiments in addicted populations is that in our heroin addicts, baseline $\left[{ }^{11} \mathrm{C}\right]$-raclopride binding is the same as in controls (Table 4) rather than being reduced. This suggests that chronic opioid use is not down-regulating dopamine $\mathrm{D}_{2}$-receptor levels as suggested for alcohol ${ }^{24}$ and stimulants. ${ }^{1,7}$ In addition in these populations, dopamine release has been reported, albeit blunted in some. By contrast, one previous study has reported reduced dopamine $\mathrm{D}_{2}$-receptor levels in opioid dependence; ${ }^{25}$ however, direct comparison with our study is difficult as the protocols and patient populations were different. Further evidence that the dopamine system is not desensitised in our population is the data for one heroin addict recruited in study 1 who, despite appearing un-intoxicated, subsequently tested positive to amphetamine on urine screening. He had approximately $30 \%$ lower $\left[{ }^{11} \mathrm{C}\right]$-raclopride binding potential in all regions compared with all the other participants (Table 4). This suggests that the dopamine system in our heroin addicts remains sensitive to amphetamine-induced reduction in $\left[{ }^{11} \mathrm{C}\right]$-raclopride binding and confirms that our scanning and analysis method was able to measure the known effect of amphetamine.

The effects of another opioid agonist, alfentanil given by infusion, have been reported in two dopamine receptor PET studies designed to explore analgesia in healthy volunteers. ${ }^{26,27}$ The first showed a $6 \%$ increase in $\left[{ }^{11} \mathrm{C}\right]$-raclopride in the striatum ${ }^{26}$ and the second reported that $\left[{ }^{11} \mathrm{C}\right]-\mathrm{FLB}-457$ binding was increased by a small amount in several cortical regions. ${ }^{27}$ Our study is different and unique in that we examined the effects of a substantial dose of hydromorphone and a standard heroin 'hit' in addicted individuals who continue to use it for its euphoriant effects and were expecting to get such effects from the injected dose.

Our findings raise fundamental questions about the role of dopamine in human opioid addiction. We have demonstrated a dissociation between the subjective 'high' and functional impairment induced by heroin and a dopamine response of comparable size to that associated with a 'high' produced by other misused drugs. There are no pre-clinical studies that have examined a comparable animal model.

One possible unifying explanation is that the level of dopamine release and $\left[{ }^{11} \mathrm{C}\right]$-raclopride displacement provoked by stimulants may be correlated with, but not necessary for, the addictive properties of these drugs. It could be that a dopamine signal in the shell of the nucleus accumbens is required by all misused drugs, but that this is too small to be detectable with PET and that the detectable dopamine signal is merely a corollary pharmacological effect of the stimulants. Although on the surface the findings with alcohol and nicotine argue against this, they show weaker effects than those with stimulants. The alcohol data were obtained under extreme intoxication ${ }^{3}$ and the original nicotine data, ${ }^{2}$ that initially showed a large effect, have recently been extended to reveal a much smaller effect that is predominantly seen in people with one specific polymorphism of the dopamine metabolising gene $\mathrm{COMT}^{28}$ or not at all. ${ }^{29}$
It may be that drugs such as nicotine and opioids, that in animals activate dopamine neurons indirectly, release little, if any, dopamine in the terminal regions, or that dopamine is rapidly taken up into the dopamine terminals. However, in the case of opioids, there are potential sites other than the dopamine system that may mediate their addictive actions. Some output regions of the basal ganglia dopamine projections, for example the globus pallidus, have high opioid receptor densities that could be the 'down-stream' target for $\mu$-opioid agonists. ${ }^{30}$

\section{Previous animal models}

Animal literature has shown that there is a dopamine response to opioids, although it is much smaller than that of stimulants (below a 300\% increase compared with the stimulant-induced increase of $400-1000 \%)^{6}$ and is maximal in the shell of the nucleus accumbens at the terminal site of projections of the opioid sensitive neurons in the ventral tegmental area. ${ }^{6}$ Measures of the sensitivity of $\left[{ }^{11} \mathrm{C}\right]$-raclopride to changes in extracellular dopamine concentration are highly variable, ranging in estimates from $8: 1$ to $44: 1$ (\% increase dopamine:\% decrease $\left[{ }^{11} \mathrm{C}\right]$-raclopride) and this relationship may vary with the individual and the nature of the challenge. ${ }^{31}$ Therefore, changes of this comparatively small magnitude, particularly if highly localised, may not be detectable with $\left[{ }^{11} \mathrm{C}\right]$-raclopride PET, even with movement correction and the latest image analysis techniques.

\section{A possible alternative role for dopamine}

A compelling alternative hypothesis is that the role of dopamine is not to signal the rewarding properties of misused drugs, but as a signal related to drug 'wanting' - the incentive-sensitisation theory. ${ }^{32}$ Clinically, the subjective response to stimulants includes the component of 'wanting', as well as 'rush' and 'high', with the 'wanting' often leading to bingeing. This experience of 'wanting' has also been shown to correlate with $\left[{ }^{11} \mathrm{C}\right]$-raclopride binding changes in healthy volunteers given an amphetamine challenge. ${ }^{33}$ In contrast, subjective responses to opioids are characterised only by 'rush', 'high' and intoxication, as we found in this study. The drug 'wanting' component of opioid addiction is most closely associated with the period between acquisition of the drug and its subsequent consumption. If the dopamine response to misused drugs is related to the 'wanting' phase rather than the 'liking' phase, then it would be expected that dopamine would be associated with acute administration of stimulants; however, in the case of opioids, the dopamine release would be maximal when the drug was being anticipated or expected, not after it has just been administered. It has already been shown using functional magnetic resonance imaging that the 'craving' induced by cocaine administration is associated with activation of the dopamine-rich nucleus accumbens, whereas the 'rush' and 'high' are not. ${ }^{34}$ This suggests that, at least in the case of opioid addiction, manipulation of drug expectation would be a more fruitful area of future research.

In summary, our study argues against dopamine having the same supremacy as the causative and maintaining agent in opioid addiction as has been shown for human stimulant addiction.

\section{Limitations}

Our participants were long-term addicts on methadone maintenance treatment who were studied a few hours after their daily methadone dose was due, but who were not in acute withdrawal. We felt that this was the best compromise as similar opioid doses given to drug-naïve individuals would have caused unacceptable levels of nausea and respiratory depression, and 
waiting for higher levels of withdrawal to emerge would have had the potential to cause increased head movement and other potential confounds.

As our sample population were long-term users of opioids with a mean duration of use of 11.6 years it may not be possible to extrapolate our results to non-dependent opioid users. It is therefore impossible to say from these data whether dopamine may still have a key role in initiation into opioid use.

All our participants were current smokers. We do not think that this detracts from our results as this is representative of the opioid-dependent population. It is also unlikely to have affected the results as all participants were not in nicotine withdrawal at the time of the scan start when the $\left[{ }^{11} \mathrm{C}\right]$-raclopride was injected, and the protocol was identical for drug and placebo scanning sessions. It is possible that this may have affected the comparison between our sample and the historical control group; however, it is more likely that this would have increased any observed difference (i.e. cause type I rather than type II error).

It is possible that the sample size of eight in the heroin group and six in the hydromorphone group is the reason for our finding of no effect. We consider this unlikely as there was no trend in either direction with participants' results being distributed evenly between an increase and decrease in $\left[{ }^{11} \mathrm{C}\right]$-raclopride binding.

Mark R.C. Daglish, MBChB, MRCPsych, Psychopharmacology Unit, University of Bristol, Bristol, and MRC Clinical Sciences Centre, Hammersmith Hospital, London, UK Tim M. Williams, MBChB,MRCPsych, Psychopharmacology Unit, University of Bristol, Tim M. Williams, MBChB,MRCPsych, Psychopharmacology Unit, University of B
and Bristol Specialist Drug Service, Bristol, and MRC Clinical Sciences Centre, Hammersmith Hospital, London, UK; Sue J. Wilson, PhD, Psychopharmacology Unit, University of Bristol, Bristol, UK; Lindsay G. Taylor, MSc, Psychopharmacology Unit, University of Bristol, Bristol, and MRC Clinical Sciences Centre, Hammersmith Hospital, London, UK; Chin B. Eap, PhD, Unit of Biochemistry and Clinical Psychopharmacology, Centre for Psychiatric Neurosciences, Hospital of Cery, Prilly, switzerland; Marc Augsburger, PhD, Christian Giroud, PhD, Laboratory of Forensic Switzerland; Marc Augsburger, PhD, Christian Giroud, PhD, Laboratory of
Toxicology and Chemistry, Institute of Forensic Medicine, CHUV, Lausanne, Switzerland; David J. Brooks, MD, DSC, FRCP, FMedSci, MRC Clinical Sciences Centre, Hammersmith Hospital, London, UK; Judy S. Myles, MBBCh, BAO, FRCPsych, Bristol Specialist Drug Service, Stokes Croft, Bristol, UK; Paul Grasby, BSC, MBBS, DCH, MRCPsych, MD, FRCP, FMedSci, MRC Clinical Sciences Centre, Hammersmith Hospital, London, UK; Anne R. Lingford-Hughes, MA, PhD, BMBCh, MRCPsych, Psychopharmacology Unit, University of Bristol, Bristol, and MRC Clinical Sciences Centre, Hammersmith Hospital, London, UK; David J. Nutt, DM, FRCP, FRCPsych, Centre, Hammersmith Hospital, London, UK; David J. Nutt, DM, FRCP,
FMedSci, Psychopharmacology Unit, University of Bristol, Bristol, UK.

Correspondence: Professor David J. Nutt, Psychopharmacology Unit, University of Bristol, Dorothy Hodgkin Building, Whitson Street, Bristol BS1 3NY, UK. Email: david.j.nutt@bristol.ac.uk

First received 5 Jun 2007, final revision 13 Jan 2008, accepted 24 Jan 2008

\section{Acknowledgements}

This work was funded by a Programme Grant from the Medical Research Council, UK.

\section{References}

1 Schlaepfer T, Pearlson G, Wong D, Marenco S, Dannals R. PET study of competition between intravenous cocaine and $\left[{ }^{11} \mathrm{C}\right]$ raclopride at dopamine receptors in human subjects. Am J Psychiatry 1997; 154: 1209-13.

2 Brody A, Olmstead R, London E, Farahi J, Meyer J, Grossman P, Lee G, Huang J, Hahn E, Mandelkern M. Smoking-induced ventral striatum dopamine release. Am J Psychiatry 2004; 161: 1211-8.

3 Boileau I, Assaad J, Pihl R, Benkelfat C, Leyton M, Diksic M, Tremblay R, Dagher A. Alcohol promotes dopamine release in the human nucleus accumbens. Synapse 2003; 49: 226-31.

4 Volkow N, Wang G, Fowler J, Logan J, Gatley S, Wong C, Hitzemann R, Pappas $\mathrm{N}$. Reinforcing effects of psychostimulants in humans are associated with increases in brain dopamine and occupancy of $D(2)$ receptors. J Pharmacol Exp Ther 1999; 291: 409-15.

5 Gerrits M, Ramsey N, Wolterink G, Van Ree J. Lack of evidence for an involvement of nucleus accumbens dopamine D1 receptors in the initiation of heroin self-administration in the rat. Psychopharmacology 1994; 114: 486-94
6 Di Chiara G, Imperato A. Drugs abused by humans preferentially increase synaptic dopamine concentrations in the mesolimbic system of freely moving rats. Proc Natl Acad Sci USA 1988; 85: 5274-8.

7 Volkow N, Wang G, Fowler J, Logan J, Gatley S, Hitzemann R, Chen A, Dewey $\mathrm{S}$, Pappas N. Decreased striatal dopaminergic responsiveness in detoxified cocaine-dependent subjects. Nature 1997; 386: 830-3.

8 World Health Organization. International Statistical Classification of Diseases and Related Health Problems (ICD-10). World Health Organization, 1992.

9 Gunn R, Lammertsma A, Hume S, Cunningham V. Parametric imaging of ligand-receptor binding in PET using a simplified reference region model. Neuroimage 1997; 6: 279-87.

10 Mawlawi O, Martinez D, Slifstein M, Broft A, Chatterjee R, Hwang D, Huang Y, Simpson N, Ngo K, Van Heertum R, Laruelle M. Imaging human mesolimbic dopamine transmission with positron emission tomography: I. Accuracy and precision of $D(2)$ receptor parameter measurements in ventral striatum. $J$ Cereb Blood Flow Metab 2001; 21: 1034-57.

11 Jenkinson C, Layte R, Wright L, Coulter A. The UK SF-36: An Analysis and Interpretation Manual. A Guide to Health Status Measurement with Particular Reference to the Short Form 36 Health Survey. University of Oxford, Department of Public Health and Primary Care, Health Services Research Unit, 1996.

12 Eysenck H, Eysenck S. Manual of the Eysenck Personality Scales (EPS Adult). Hodder and Stoughton, 1971.

13 Gossop M, Darke S, Griffiths P, Hando J, Powis B, Hall W, Strang J. The Severity of Dependence Scale (SDS): psychometric properties of the SDS in English and Australian samples of heroin, cocaine and amphetamine users. Addiction 1995; 90: 607-14.

14 Anton R, Moak D, Latham P. The Obsessive Compulsive Drinking Scale. A new method of assessing outcome in alcoholism treatment studies. Arch Gen Psychiatry 1996; 53: 225-31.

15 Martin W, Sloan J, Sapira J, Jasinski D. Physiologic, subjective and behavioural effects of amphetamine, methamphetamine, ephedrine, phenmetrazine and methylphenidate in man. Clin Pharmacol Ther 1971; 12: 245-58.

16 Jasinski D. Assessment of the abuse potential of morphine-like drugs (methods used in man). In Drug Addiction I: Morphine, Sedative/Hypnotic and Alcohol Dependence (ed W Martin): 197-258. Springer-Verlag, 1977.

17 Spielberger C, Gorsuch R, Lushene R, Vagg P, Jacobs G. Manual for the StateTrait Anxiety Inventory. Consulting Psychologists' Press, 1983.

18 Beck A, Ward C, Mendelson M, Mock J, Erbaugh J. An inventory for measuring depression. Arch Gen Psychiatry 1961; 4: 561-71.

19 Law F, Bailey J, Allen D, Melichar J, Myles J, Mitcheson M, Lewis J, Nutt D. The feasibility of abrupt methadone-buprenorphine transfer in British opiate addicts in an outpatient setting. Addict Biol 1997; 2: 191-200.

20 Melichar J, Myles J, Eap C, Nutt D. Using saccadic eye movements as objective measures of tolerance in methadone dependent individuals during the hydromorphone challenge test. Addict Biol 2003; 8: 59-66.

21 Crettol S, Deglon J, Besson J, Croquette-Krokkar M, Gothuey I, Hammig R, Monnat $\mathrm{M}$, Huttemann $\mathrm{H}$, Baumann $\mathrm{P}$, Eap CB. Methadone enantiomer plasma levels, CYP2B6, CYP2C19, and CYP2C9 genotypes, and response to treatment. Clin Pharmacol Ther 2005; 78: 593-604.

22 Dienes-Nagy A, Rivier L, Giroud C, Augsburger M, Mangin P. Method for quantification of morphine and its 3 - and 6-glucuronides, codeine, codeine glucuronide and 6-monoacetylmorphine in human blood by liquid chromatography-electrospray mass spectrometry for routine analysis in forensic toxicology. J Chromatogr A 1999; 854: 109-18.

23 Ridenour T, Maldonado-Molina M, Compton W, Spitznagel E, Cottler L. Factors associated with the transition from abuse to dependence among substance abusers. Implications for a measure of addictive liability. Drug Alcohol Depend 2005; 80: 1-14.

24 Martinez D, Gil R, Slifstein M, Hwang D, Huang $Y$, Perez A, Kegeles L, Talbot $P$, Evans S, Krystal J, Laruelle M, Abi-Dargham A. Alcohol dependence is associated with blunted dopamine transmission in the ventral striatum. Biol Psychiatry 2005; 58: 779-86.

25 Wang G, Volkow N, Fowler J, Logan J, Abumrad N, Hitzemann R, Pappas N, Pascani K. Dopamine $\mathrm{D}_{2}$ receptor availability in opiate-dependent subjects before and after naloxone-precipitated withdrawal. Neuropsychopharmacol 1997; 16: 174-82.

26 Hagelberg N, Kajander J, Nagren K, Hinkka S, Hietala J, Scheinin H. Mureceptor agonism with alfentanil increases striatal dopamine $D_{2}$ receptor binding in man. Synapse 2002; 45: 25-30.

27 Hagelberg N, Aalto S, Kajander J, Oikonen V, Hinkka S, Nagren K, Hietala J, Scheinin $\mathrm{H}$. Alfentanil increases cortical dopamine $D_{2} / D_{3}$ receptor binding in healthy subjects. Pain 2004; 109: 86-93.

28 Brody AL, Mandelkern MA, Olmstead RE, Scheibal D, Hahn E, Shiraga S, Zamora-Paja E, Farahi J, Saxena S, London ED, McCracken JT. Gene variants 
of brain dopamine pathways and smoking-induced dopamine release in the ventral caudate/nucleus accumbens. Arch Gen Psychiatry 2006; 63: 808-16.

29 Montgomery AJ, Lingford-Hughes AR, Egerton A, Nutt DJ, Grasby PM. The effect of nicotine on striatal dopamine release in man. $A\left[{ }^{11} \mathrm{C}\right]$ raclopride PET study. Synapse 2007; 61: 637-45.

30 Mitrovic I, Napier TC. Mu and kappa opioid agonists modulate ventral tegmental area input to the ventral pallidum. Eur J Neurosci 2002; 15: 257-68

31 Laruelle M. Imaging synaptic neurotransmission with in vivo binding competition techniques: a critical review. J Cereb Blood Flow Metab 2000; 20: $423-51$
32 Robinson $T$, Berridge $K$. The neural basis of drug craving: an incentive sensitization theory of addiction. Brain Res Brain Res Rev 1993; 18: 247-91.

33 Leyton M, Boileau I, Benkelfat C, Diksic M, Baker G, Dagher A. Amphetamineinduced increases in extracellular dopamine, drug wanting, and novelty seeking: a PET/ $\left[{ }^{11} \mathrm{C}\right.$ lraclopride study in healthy men. Neuropsychopharmacol 2002; 27: 1027-35.

34 Breiter $\mathrm{H}$, Gollub R, Weisskoff $\mathrm{R}$, Kennedy $\mathrm{D}$, Makris $\mathrm{N}$, Berke J, Goodman J, Kantor H, Gastfriend D, Riorden J, Mathew R, Rosen B, Hyman S. Acute effects of cocaine on human brain activity and emotion. Neuron 1997; 19 591-611.

\section{Poems by} doctors

\section{Doppelgänge}

Behind the edge of what I see

There sits a little man of grey.

My friends, they say good night to me;

He does not go away.

He watches me, dull, drunk, polite,

Without a smile, without a sneer.

I wake and shiver in the night

To whispers in my ear.

And when I fell in love with you

And there was neither night nor day,

You did not know you slept with two

He did not go away.

\section{Friend}

I must admire, we are so closely grown, His little elegance of thought and pen, Integrity that trips but now and then, His very failings such I would condone.

One day he will be put upon the shelf And my solicitude will have to end.

It will be mine no more to serve my friend, So changed I shall no longer know myself.

\section{Re-Encounter}

They are not changed, those indiscreet

Young limbs of but two years ago;

But clothes you now from head to feet

The certainty I used to know.

Now you your half-forgetful smile

Remembering another give,

And welcome, telling me the while

That I was young once - and yet live.

Republished with permission from Slater, E. (1968) The Ebbless Sea, Poems (1922-1962). Outposts Publications.

Eliot Slater (1904-1983) is best known for his seminal applications of rigorous basic statistical and genetic research methodologies to the study of mental health problems and for demonstrating that temporal lobe epilepsy was associated with schizophrenia-like psychoses. Yet strong literary interests and associations ran through his life. He married Lydia Pasternak, the sister of the Russian poet and novelist, and was himself a published poet. In retirement he undertook and completed a PhD (later published) in which he made a strong case for shakespeare as author of an early play of disputed authorship (Edward III) by the use of sophisticated numerical measures (cliometrics). He was also an Editor of the British Journal of Psychiatry (1961-1972) who introduced the yellow colour for the cover. 